\title{
Exploring the Key Factors that Lead to Intentions to Use Al Fashion Curation Services through Big Data Analysis
}

\author{
Eunjung Shin ${ }^{1}$ and Ha Sung Hwang ${ }^{2}$ \\ ${ }^{1}$ Department of Clothing \& Textiles, Yonsei University \\ Seoul, South Korea \\ ${ }^{2}$ Department of Media and Communication, Dongguk University \\ Seoul, South Korea \\ [e-mail: ej_shin@yonsei.ac.kr, hhwang@dongguk.edu] \\ *Corresponding author: Ha Sung Hwang
}

Received August 16, 2021; revised October 18, 2021; accepted November 9, 2021;

published February 28, 2022

\begin{abstract}
An increasing number of companies in the fashion industry are using AI curation services. The purpose of this study is to investigate perceptions of and intentions to use AI fashion curation services among customers by using text mining. To accomplish this goal, we collected a total of 34,190 online posts from two Korean portals, Naver and Daum. We conducted frequency analysis to identify the most frequently mentioned keywords using Textom. The analysis extracted "various," "good," "many," "right," and "new" at the highest frequency, indicating that consumers had positive perceptions of AI fashion curation services. In addition, we conducted a semantic network analysis with the top-50 most frequently used keywords, classifying customers' perceptions of AI fashion curation services into three groups: shopping, platform, and business profit. We also identified the factors that boost continuous use intentions: usability, usefulness, reliability, enjoyment, and personalization. We conclude this paper by discussing the theoretical and practical implications of these findings.
\end{abstract}

Keywords: Artificial Intelligence (AI), Big Data, Curation, Fashion, Text Mining

A preliminary version of this paper appeared in APIC-IST 2021, June 16-20, Busan, Korea and was selected by the conference review process. 


\section{Introduction}

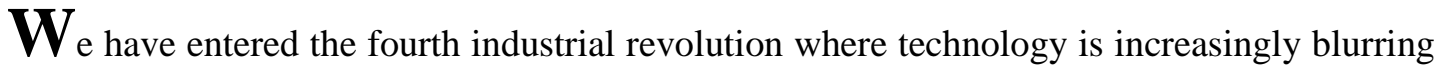
the boundary between the physical and digital spheres [1], and artificial intelligence (AI), manifesting in machines that exhibit aspects of human intelligence, is increasingly utilized not only in retail and service but also as a part of our daily lives [2]. Indeed, AI technologies like Apple's Siri, Amazon's Alexa, and the algorithms used on e-commerce platforms are becoming commonplace.

As in many industries, the use of a combination of AI technologies is rapidly expanding in the fashion industry. Worldwide, revenue from the e-commerce fashion industry is expected to increase from $\$ 481$ billion USD in 2018 to $\$ 712$ billion USD by 2022. This highlights the growing demand for online apparel shopping, which is motivating businesses to build more advanced AI fashion design. When customers shop online, digital platforms present recommendations that appear to be personalized specifically for them. These recommendations are the work of what are typically referred to as algorithms or AI curation services.

An increasing number of companies in the fashion industry are using AI recommendation systems. For example, Hugo Boss launched the "Hugo Boss AI Capsule Collection," in which an AI system independently developed a new collection; in a similar vein, Tommy Hilfiger, IBM, and the Fashion Institute of Technology collaborated to introduce "Reimagine Retail," which seeks to identify future industry trends and improve design processes [3]. AI fashion curation services that analyze consumers' preferences and provide "custom-tailored" fashion choices have also emerged. Examples of such services include Stitch Fix, a fashion startup business in the United States, and StyleShare in Korea [4], both of which use data and machine learning to send curated selections of clothing and accessories to customers.

Market research suggests that AI services are likely to become important contributors to the fashion industry [5]. As guardians of specialized knowledge, these services can help consumers compare products and make informed purchase decisions by filtering vast amounts of product information online [6]. Moreover, AI services help users create stylish outfits using items they already have, or purchase additional items that go well with their existing wardrobes. The fact that the fashion industry depends on consumers' tastes and preferences makes the individually tailored information these services provide increasingly important [7].

Nonetheless, little is known about the preferences and perceptions of customers who use AI-based fashion curation services [8]. Sundar (2020) [9] proposed a framework for humanAI-interaction and called for more research in this area. Researchers still need to address how customers perceive AI fashion curation services and how they experience them [10]. Therefore, this study aims to explore users' perceptions of AI fashion curation and intentions to continue using AI fashion curation. By using big data analysis, the study, especially, tries to answer the following questions: (1) What keywords are most frequently mentioned in social media content regarding AI fashion curation services? (2) In social media content, what keywords relate to perceptions of AI fashion curation services? (3) In social media content, what keywords relate to intentions to continue using AI fashion curation services?

Many previous studies have utilized survey methods to identify the key factors that impact user satisfaction. However, the development of social media has enabled customers to share their experiences online by leaving text comments online. Accordingly, researchers have begun using text mining to analyze online reviews and posts, because such posts and reviews accurately reflect customer experiences and provide information that is more reliable than the information provided by companies [11]; such analyses have become a new method for 
examining the factors that most substantially impact customer perceptions of services [12].

Given that AI services influence what people have chosen in the past, what they choose in the present, and what they will choose in the future [13], examining how people see and use AI fashion curation services is crucial. Accordingly, this study uses text (online posts) mining techniques to analyze customers' experiences and intentions to use AI fashion curation systems. Specifically, we apply text mining, natural language processing, and morphological analysis to examine text and keywords in online posts related to AI fashion curation from between January 1, 2018 and December 31, 2020.

We expect the results of this study will have meaningful implications for the fashion industry. Theoretically, our study will elucidate the uses and effects of AI fashion curation services by revealing why consumers use them, how they perceive them, and how they intend to use them in the future. In practice, fashion companies can use analyses of online posts as a marketing tool. Given that the development of AI technology will provide solutions that will help the future fashion industry cope with rapidly changing consumer preferences and consumption patterns, our results will provide important insights that will help improve AI fashion curation services in the e-commerce fashion industry.

\section{Literature Review}

\subsection{Defining Al}

AI is a broad concept; its definition encompasses a variety of terms including "machine intelligence," "intelligence agents," "intelligent behavior," "intelligent systems," and "algorithms" [14]. Since John McCarthy first defined it in 1956, it has developed into a computer science discipline in the United States and has remained a persistent theme in science fiction. McCarthy originally defined AI as the "science and engineering of making intelligent machines, especially intelligent computer programs" [15], but definitions of AI vary among researchers. For example, Shankar (2018) [16] defined it as "programs, algorithms, systems and machines that demonstrate intelligence" (p. vi) and others have considered it a form of self-learning technology [17]. Recently, AI has become an essential technology in the eyes of firms worldwide [18].

Yunhe (2016) [19] argued that the focus of AI today differs significantly from that of the past 60 years; AI has numerous dimensions, including machine learning, deep learning, and robotics [20] and such AI technologies aim to do tasks involving human intelligence, by creating "artificial” systems to solve complex environmental problems. Therefore, AI gives companies a competitive advantage [21] and is now becoming one of the biggest disrupters in the business sector [22].

Indeed, whether we know it or not, AI has become part of our lives and a key feature of many services and industries [23]. Many companies currently use AI. For example, Hilton Worldwide employs a robotic concierge named "Connie," who is responsible for personalizing guests' experiences, providing information, and addressing guests' general needs [24]. Similarly, North Face utilizes an online AI application developed using IBM's Watson technology to help customers choose the most suitable jacket [25].

\subsection{Al in the Fashion Industry}

The use of AI in the fashion market has expanded rapidly. The AI in Fashion Market Research Report 2021 predicted that global spending on AI in the fashion market would increase from USD 229 million in 2019 to USD 1,260 million by 2024, and that the Compound Annual 
Growth Rate (CAGR) would increase 40.8\% during the forecast period [26]. In omnichannel retailing, AI is used to personalize shopping experiences with personalized searches, personalized recommendations, and personalized prices and promotions [27]. AI is also used to customize store layouts to maximize customer satisfaction and sales opportunities [28].

The representative companies using AI for fashion include Amazon, which has implemented an AI designer algorithm that can design apparel by copying the design styles of many in-vogue clothes and applying them to new clothing items. H\&M allows its consumers to interact with a chatbot through the Kik app. It also enables consumers to select filters, recommendations, and style preferences. Meanwhile, fashion retailers are now also using AI and machine learning algorithms to understand fast-changing customer needs and expectations. For example, an online personal styling company, Stitch Fix uses ML algorithms to improve both customer experiences and supply chain management.

In Korea, AI is becoming an important asset in the e-commerce industry as well. A recently published research report announced that the domestic AI market will grow at a CAGR of $17.8 \%$ over the next five years and reach a size of more than USD 55 million by $2023 .{ }^{1}$ The companies that have introduced AI fashion platforms include Kakao. KaKao originally operated "Kakao Style," which it subsequently merged with "ZigZag," a fashion platform that uses AI to provide personalized product recommendations. When a new user selects a desired photo from among the various coordinating style photos provided by the AI on ZigZag, the platform presents the user with products similar to the photo by sorting them based on popularity, age, and style. If a user long-clicks on a specific product, they receive recommendations for 100 additional similar products. As of the end of 2020, ZigZag had about 4,000 shopping malls with 3 million monthly users, and its 2021 annual turnover is expected to reach USD 1 billion. ${ }^{2}$

\subsection{Perceptions of and Intentions to Use AI}

Since AI is widely used in various sectors, many recent studies have examined user perceptions of AI. Tussyadiah and Miller (2019) [29] examined user awareness of AI, classifying users into three groups: laggards, aficionados, and realists. Most users are realists, believing that AI technology has both benefits and risks. Users who perceive AI-based products and services as having high utility compared to other products consider AI technology an effective means of changing buying behavior [30]. In particular, since content curation algorithms purport to show users items that are relevant to them, users base their acceptance of AI on the usefulness and convenience of such algorithms. Indeed, Shin (2020) [13] found that users who use personalized recommendation algorithms such as Netflix perceive fairer, more accountable, transparent, and explainable AI algorithms as more trustworthy and useful.

Recently, AI technology has been used in the retail fashion industry to improve consumer experiences [31]. Several studies examining consumer willingness to adopt AI systems in the fashion market have identified key factors that influence the adoption of AI. For example, Niemelä, Arvola, and Aaltonen (2017) [32] found that hedonic motivation is the main factor influencing consumers' intentions to use AI systems in retail stores. Meanwhile, Song (2017) [33] identified perceived usefulness, social capability, and device appearance as the determinants of service robot adoption. However, Stock and Merkle (2017) [34] found that customers' expectations regarding AI devices, including their expectations regarding service

\footnotetext{
${ }^{1}$ https://www.idc.com/getdoc.jsp?containerId=prAP46186820

${ }^{2}$ http://www.aitimes.com/news/articleView.html?idxno=138024
} 
quality, influence their intentions to use AI devices. In addition, other studies have identified reliability, dependability, transparency, explainability, convenience, and ease of use as critical determinants of customer satisfaction with AI curation services [8, 13, 35]. Choi, Cha, and Choi (2018) [36] reported that AI-based curation shopping services that offer recommendations and personalized products have higher usability and reliability ratings, leading to favorable consumer attitudes and bolstering use and purchase intentions [36]. Overall, perceived usefulness, ease of use, reliability, and joyfulness are believed to contribute substantially to consumers' adoption and continuous use of AI.

\subsection{Big Data Analysis}

Big data involves a series of processes that store, collect, mine, analyze, and commercialize large volumes of data. It is widely used in various fields to diagnose current situations and make future predictions.

Key big data analysis methods include text mining of social data and web documents, web mining, opinion mining, network analytics, data visualization, correlation analysis, artificial neural networks, and clustering [37]. Among these methods, text mining and semantic network analytics are the main approaches used to extract information from online content and analyze it.

Text mining refers to the identification of unknown useful patterns and knowledge in text using information retrieval, information extraction, and natural language processing techniques [38]. The general text mining process involves several steps including data collection, data refinement, data analysis, and the management of information systems. The fact that text mining begins with keyword analysis makes it particularly useful for identifying various discussions and changes related to social phenomena and issues [39].

Meanwhile, semantic network analysis examines network connectivity architectures and connection strengths to determine which messages are propagated through which channels and who they can affect. A big advantage of semantic network analysis is that it can be used to visualize the patterns and semantic structures of communication processes by extracting structured information from non-standardized text data [40]. Semantic network analysis is a prominent part of the data mining field that deals with key contexts, topics, and sentiment identification [41].

Recently, researchers have actively conducted text mining research in the fashion industry. Beheshti-Kashi and Toben (2016) [42] applied text mining to social media data to analyze fashion trends and categorize design features. Rizun and Kucharska (2018) [43] examined customers' interactions with fashion brands using a set of text mining algorithms. Likewise, An and Park (2018) [44] applied text mining and semantic network analysis to explain the correlations between fashion design features. Following these studies, we apply text mining and semantic network analysis to examine perceptions of AI fashion curation services and intentions to use those services among social media users.

\section{Method}

\subsection{Data collection}

The data was collected from newspaper articles and postings from online communities and blog from two social media sites, Naver and Daum, which are representative portals in Korea. For the data collection we used Textom, a software program that analyzes the text of online postings. Textom creates a data set by collecting various text on the Internet at a high speed. 
Using keywords such as "AI fashion curation," "artificial intelligence fashion curation," "AI fashion recommendation," and "fashion recommendation," we collected text data related to “AI fashion curation” between January 1, 2018 and December 31, 2020, and obtained 34,190 cases: 18,248 from Naver and 15,492 from Daum.

After collecting the data, we extracted only verbs, adjectives, and nouns through morpheme analysis by using Espresso $\mathrm{K}$, morpheme analyzer. For the purpose of the study special characters, symbols, numbers, words in English, and pronouns were excluded. Then stopwords were removed for the data refinement. Stop words are the words frequently appear in the text without having much content information (e.g., prepositions, conjunctions, etc.), and stop words removal is known as a common filtering [45]. Lastly, we combined or unify synonyms.

\subsection{Data analysisg}

For the data analysis, first we conducted frequency analysis and generated a matrix by analyzing keywords using Textom. Second, we performed TF-IDF (Term Frequency Inverse Document Frequency) analysis to analyze keywords based on word importance values. Third, we used UCINET 6.0 and NetDraw software programs to conduct semantic network analysis of the collected data. UCINET is an analysis tool that enables network analysis based on text indexes. It reveals the structure of linkages between keywords [46]. In addition, for visualization, we used NetDraw to clearly trace the relationships between keywords and to visualize the networks between AI fashion curation-related keywords in online posts. Forth, we performed CONCOR (CONvergence of iteration CORrealtion) analysis with the final refined 50 high frequency keywords to analyze similar clusters by calculating the structural equivalence of keywords. Lastly, we used frequency analysis to identify keywords related to use intentions.

\section{Results}

\subsection{Text Mining Results}

To identify important AI fashion curation-related keywords on social media, we used text mining analysis techniques such as the keyword frequency analysis and TF-IDF analysis.

\subsubsection{Keyword Frequency Analysis}

Table 1 lists the top-30 most frequently mentioned AI fashion curation-related keywords. The five keywords with the highest use frequency were "service" $(3,514)$, "technology" $(2,824)$, "simple payment” (2807), "Dibidibi” (2721), and "video commerce” (2651). As indicated by keywords, it seems that people perceived AI fashion curation as service or technology. The result also reflects the recent trend in the fashion market, as video commerce becomes a new marketing method utilizing AI curation for fashion and beauty products, and Dibidibi is being introduced as a new commerce platform which adopts AI curation service. Although many keywords related to shopping ("blog shopping," "customer," "blog market," "shopping," and "product"), only two of the top-30 keywords concerned fashion- "fashion platform" and “design.” 
Table 1. Top-30 most frequently used fashion curation-related words from 2018-2020

\begin{tabular}{|c|c|c|}
\hline Rank & Keyword & Frequency \\
\hline 1 & Service & 3514 \\
\hline 2 & Technology & 2824 \\
\hline 3 & Simple payment & 2807 \\
\hline 4 & Dibidibi & 2721 \\
\hline 5 & Video commerce & 2651 \\
\hline 6 & Goods & 2032 \\
\hline 7 & Application & 1661 \\
\hline 8 & Customer & 1517 \\
\hline 9 & Stock & 1441 \\
\hline 10 & Analysis & 1428 \\
\hline 11 & Company & 1322 \\
\hline 12 & Blog shopping & 1314 \\
\hline 13 & Platform & 1293 \\
\hline 14 & Blog market & 1223 \\
\hline 15 & Beauty & 1212 \\
\hline 16 & Month & 1185 \\
\hline 17 & Use & 1183 \\
\hline 18 & Individual & 1175 \\
\hline 19 & Data & 1166 \\
\hline 20 & Supply & 1159 \\
\hline 21 & Today & 1141 \\
\hline 22 & Naver & 1141 \\
\hline 23 & Shopping & 1130 \\
\hline 24 & Take & 1125 \\
\hline 25 & Various & 1099 \\
\hline 26 & Stock item & 1046 \\
\hline 27 & News & 1046 \\
\hline 28 & Fashion platform & 1045 \\
\hline 29 & Product & 1019 \\
\hline 30 & Design & 988 \\
\hline
\end{tabular}

\subsubsection{TF-IDF Analysis}

While frequency analysis only reveals the use frequency of text extracted from text mining, TF-IDF is a statistical method that uses weights to determine the importance of text in a given document [46]. TF-IDF analysis calculates values for each word in a document through an inverse proportion of the frequency of the word in a particular document to the percentage of documents the word appears in. The outputs of TF-IDF indicates that the keywords having greater TF-IDF score would come on the top in decreasing order [47].

Because words with high TF-IDF numbers imply a strong relationship with the document they appear in, we conducted TF-IDF analysis to examine the importance of the keywords found from the frequency analysis and to see the ranking change when compared with the frequency analysis result.

Table 2 shows the results or our TF-IDF analysis. The five keywords with the highest TFIDF were "service", "technology", "simple payment”, "Dibidibi”, and "video commerce," indicating that these words have strong relationship with the perception of AI fashion curation. The study also found that there was not ranking change among these top five keywords, when compared with frequency analysis result. It can be said that the word with higher frequency 
mentioned on the social media seems to be important, in particular, in the case of AI fashion curation service.

However, comparing the TF-IDF and frequency analysis results, we found that "Naver" went from 22nd in the frequency analysis to 13th in TF-IDF analysis, indicating that the portal site's name itself is an important word for AI fashion curation. Similarly, "stock item" went from 26th in the frequency analysis to 24th in the TF-IDF analysis. This suggests that the importance of the word "stock" has increased because AI is in the spotlight in stock stocks. On the other hand, we found that "blog shopping" and "blog market" dropped from 12th and 14th, respectively, in the frequency analysis to 15th and $20^{\text {th }}$, respectively, in the TF-IDF analysis. This implies that despite their high use frequency, these two keywords are less important to AI fashion curation than they initially appear.

Table 2. TF-IDF Results from 2018-2020

\begin{tabular}{|c|c|c|}
\hline Rank & Keyword & TF-IDF \\
\hline 1 & Service & 7506.175 \\
\hline 2 & Technology & 6384.516 \\
\hline 3 & Simple payment & 5951.62 \\
\hline 4 & Dibidibi & 5883.1 \\
\hline 5 & Video commerce & 5772.439 \\
\hline 6 & Goods & 5401.681 \\
\hline 7 & Application & 4522.175 \\
\hline 8 & Customer & 4398.243 \\
\hline 9 & Stock & 4306.538 \\
\hline 10 & Analysis & 4113.842 \\
\hline 11 & Company & 3978.109 \\
\hline 12 & Platform & 3936.457 \\
\hline 13 & Naver & 3917.545 \\
\hline 14 & Beauty & 3829.215 \\
\hline 15 & Blog shopping & 3783.424 \\
\hline 16 & Use & 3674.948 \\
\hline 17 & Data & 3673.362 \\
\hline 18 & Month & 3633.466 \\
\hline 19 & Individual & 3633.382 \\
\hline 20 & Blog market & 3609.18 \\
\hline 21 & Shopping & 3589.656 \\
\hline 22 & Supply & 3554.809 \\
\hline 23 & Today & 3501.698 \\
\hline 24 & Stock Item & 3457.6 \\
\hline 25 & Take & 3455.703 \\
\hline 26 & Various & 3417.159 \\
\hline 27 & News & 3354.365 \\
\hline 28 & Product & 3315.133 \\
\hline 29 & Design & 3272.812 \\
\hline 30 & Fashion Platform & 3250.256 \\
\hline
\end{tabular}

\subsection{Perception Results}

We used two methods to analyze AI fashion curation-related perceptions on social media. First, we extracted only keywords that corresponded to adjectives included in the keyword frequency 
analysis results, which were identified via text mining. Second, we used CONCOR analysis, a network analysis method, to identify the subgroups of these keywords so as to understand their intercorrelations.

\subsubsection{Frequency Analysis}

The frequency analysis for adjectives derived keywords such as "various" (1099), "good" (866), "many" (740), "right" (700), and "new" (615) at the highest frequencies. In particular, it extracted numerous adjectives related to newness, including "new" (615), "latest” (418), and "recent" (352). In addition, the analysis derived many positive adjectives such as "good" (866), “interesting” (315), "favorite” (177), and "entertaining” (168) at high frequencies. Moreover, the analysis also extracted keywords describing usability, including "easy” (230), "convenient" (136), and "helpful” (122). However, it only derived two negative adjectives- "unaware" (182) and "difficult" (163). These results indicate that consumers have positive attitudes toward AI fashion curation services, suggesting that they perceive them as new, useful, and enjoyable rather than unknown and difficult to use.

Table 3. Adjectives Extracted from the Frequency Analysis

\begin{tabular}{|c|c|c|}
\hline Rank & Keyword & Frequency \\
\hline 1 & Various & 1099 \\
\hline 2 & Good & 740 \\
\hline 3 & Many & 700 \\
\hline 4 & Right & 615 \\
\hline 5 & New & 531 \\
\hline 6 & High & 418 \\
\hline 7 & Up-to-to-date & 352 \\
\hline 8 & Recent & 315 \\
\hline 9 & Interesting & 291 \\
\hline 10 & Fast & 230 \\
\hline 11 & Easy & 279 \\
\hline 12 & Well-matched & 232 \\
\hline 13 & Important & 182 \\
\hline 14 & Unaware & 177 \\
\hline 15 & Favorite & 168 \\
\hline 16 & Entertaining & 163 \\
\hline 17 & Difficult & 137 \\
\hline 18 & Famous & 136 \\
\hline 19 & Convenient & 122 \\
\hline 20 & Helpful & \\
\hline & & \\
\hline
\end{tabular}

\subsubsection{CONCOR (CONvergence of iteration CORrealtion) Analysis}

CONCOR analysis identifies similarities between groups by analyzing the correlations between keywords. In general, semantic network analysis aims to figure out the relationships between words and visualize the connections between them. To visualize the relationships between keywords related to AI fashion curation, we conducted a CONCOR analysis of the top-50 most frequently derived words in the frequency analysis. Fig. 1 presents the results.

The CONCOR analysis identified three groups. The first group consisted of keywords such as "information," "search," "product," "style," and "design." Since these words relate to shopping, we named the first group "shopping." We named the second group "platform" because it consisted of keywords such as "shopping platform," "platform," "application," and 
"startup." Finally, we named the third group "business profit" because the main keywords included "company," "investment," "Naver," "development," and "stock," which referred to AI companies (e.g., Naver) and their potential profits profit (e.g., investment, development, stock). Table 4 presents the detailed results.

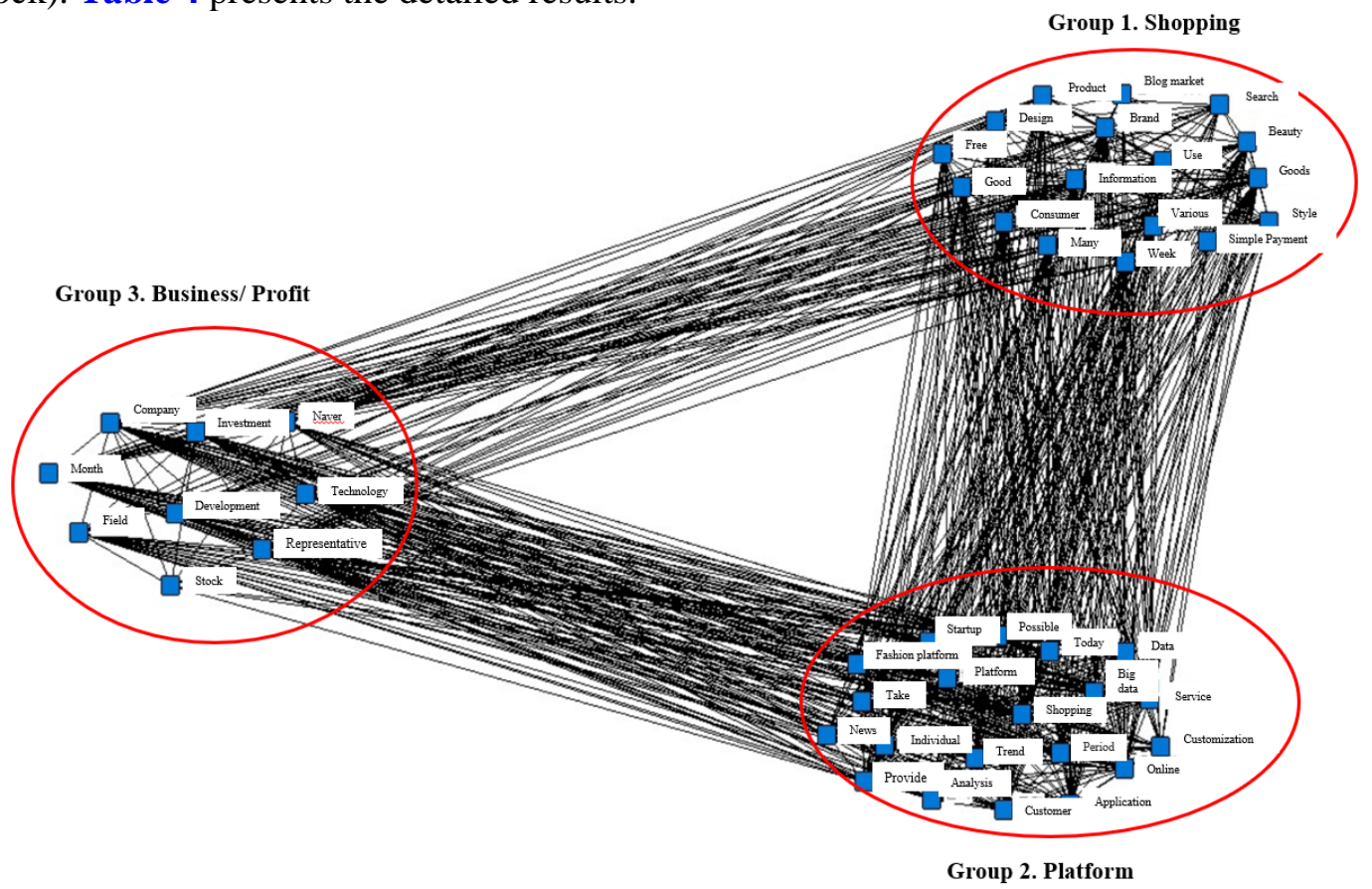

Fig. 1. The 3 clusters generated by the CONCOR analysis

Table 4. Keywords Comprising the 3 Groups Identified by the CONCOR Analysis

\begin{tabular}{|c|c|}
\hline & Extracted words \\
\hline shopping & $\begin{array}{l}\text { Product/ Blog market/ Search/ Design/ Brand/ Beauty/ Free/ Use/ Good/ } \\
\text { Information/ Goods/ Consumer/ Various/ Style/ Many/ Week/ Simple Payment }\end{array}$ \\
\hline Platform & $\begin{array}{c}\text { Startup/ Possible/ Fashion platform/ Platform/ Today/ Data/ Big data/ Take/ } \\
\text { News/ Individual/ Shopping/ Service/ Trend/ Period/ Customization/ } \\
\text { Provide/ Analysis/ Customer/ Application/ Online }\end{array}$ \\
\hline $\begin{array}{c}\text { Business/ } \\
\text { profit }\end{array}$ & $\begin{array}{l}\text { Company/ Investment/ Naver/ Month/ Development/ Technology/ Field/ Stock/ } \\
\text { Representative }\end{array}$ \\
\hline
\end{tabular}

\subsection{Use Intentions Results}

From the text mining results used in the initial keyword analysis we selected keywords related to intentions of AI fashion curation based on previous studies which revealed factors affecting adoption of AI service use [13, 34, 35, 36]. Then we grouped similar keywords and named the groups corresponding to them. As shown in Table 5, five factors were identified.

The first factor, usability, consisted of keywords such as "easy," "convenient," and "comfort." The second factor, usefulness, included such keywords as "value," "help," "efficiency," and "useful." The third factor, personalization, consisted of such words as "curation,” "customized," "taste,” and "coordination.” The fourth factor, enjoyment, included such keywords "good," "new," "interesting," and "like." Lastly, the fifth factor, reliability, consisted of words such as "trust," "trustworthy," and "sense of trust." 
Table 5. Extracted Use Intentions

\begin{tabular}{|c|c|c|c|c|c|c|c|c|c|c|}
\hline & \multicolumn{2}{|c|}{ usability } & \multicolumn{2}{|c|}{ Usefulness } & \multicolumn{2}{|c|}{$\begin{array}{c}\text { Personalizati } \\
\text { on }\end{array}$} & \multicolumn{2}{|c|}{ Enjoyment } & \multicolumn{2}{|c|}{ Reliability } \\
\hline & $\begin{array}{c}\text { Keywo } \\
\text { rd } \\
\end{array}$ & $\begin{array}{c}\text { Freq } \\
. \\
\end{array}$ & Keyword & $\begin{array}{c}\text { Freq } \\
. \\
\end{array}$ & $\begin{array}{c}\text { Keywo } \\
\text { rd } \\
\end{array}$ & $\begin{array}{c}\text { Fre } \\
\mathrm{q} . \\
\end{array}$ & Keyword & $\begin{array}{c}\text { Fre } \\
\mathrm{q} . \\
\end{array}$ & Keyword & $\begin{array}{c}\text { Fre } \\
\mathrm{q} .\end{array}$ \\
\hline 1 & Easy & 230 & Help & 122 & $\begin{array}{c}\text { Curatio } \\
n\end{array}$ & 873 & Good & 866 & Trust & 67 \\
\hline 2 & $\begin{array}{c}\text { Conven } \\
\text { ient }\end{array}$ & 136 & Value & 120 & $\begin{array}{c}\text { Custom } \\
\text { ized }\end{array}$ & 785 & New & 615 & $\begin{array}{c}\text { Trustwor } \\
\text { thy }\end{array}$ & 47 \\
\hline 3 & $\begin{array}{c}\text { Comfor } \\
t\end{array}$ & 100 & $\begin{array}{c}\text { Efficienc } \\
\mathrm{y}\end{array}$ & 72 & Proper & 700 & Interesting & 315 & $\begin{array}{l}\text { A sense } \\
\text { of trust }\end{array}$ & 32 \\
\hline 4 & & & Useful & 37 & Taste & 621 & Like & 177 & & \\
\hline 5 & & & & & $\begin{array}{l}\text { Custom } \\
\text { ize }\end{array}$ & 497 & Enjoy & 168 & & \\
\hline 6 & & & & & $\begin{array}{c}\text { Coordi } \\
\text { nation }\end{array}$ & 345 & & & & \\
\hline 7 & & & & & $\begin{array}{c}\text { Daily } \\
\text { Coordi } \\
\text { nation }\end{array}$ & 327 & & & & \\
\hline 8 & & & & & Chatbot & 324 & & & & \\
\hline 9 & & & & & $\begin{array}{c}\text { Well- } \\
\text { matche } \\
\text { d }\end{array}$ & 279 & & & & \\
\hline 10 & & & & & Styling & 137 & & & & \\
\hline 11 & & & & & $\begin{array}{c}\text { Optima } \\
\text { l }\end{array}$ & 125 & & & & \\
\hline
\end{tabular}

* Freq.= Frequency

\section{Discussion}

Recently, AI, Big Data, and data mining have played increasingly important roles in fashion industry trends $[6,8,35,36,49]$, and the introduction of AI into the fashion industry has changed strategic decision-making regarding production, sales, marketing, and even fashion design [49]. Consequently, AI adoption in fashion industry has attracted great attention among researchers. In this study, we sought to elucidate the utilization of AI fashion curation services from the customer perspective by analyzing online text regarding such services from Korean social media.

In our data analysis, we extracted keywords via text mining and then conducted frequency analysis. The results showed that frequently appearing keywords related to AI fashion curation on the two social media, Naver and Daum, include such positive adjectives as "various," "good," "many," "right," and "new," indicating that users have positive perceptions of AI fashion curation services. The results also suggested that consumers perceive AI fashion curation services as useful, convenient, and helpful, as the frequency analysis indicated that the derived keywords related to those adjectives. These findings support the key points of the Technology Adoption Model. This model posits the following: (1) when people encounter a new technology, they develop specific perceptions of it; (2) specific perceptions of a new technology determine people's behavioral intentions to adopt it; and (3) two factors, perceived usefulness and perceived ease of use, affect people's behavioral intentions when it comes to using the new technology [50]. Our findings confirm that social media users have specific 
perceptions of AI fashion curation services; they believe that, as a type of new technology, AI fashion curation services are useful and convenient to use.

Moreover, our findings indicate that consumers have more positive than negative perceptions of AI fashion curation services, since our analyses extracted more positive adjectives at higher frequencies. Although AI services are considered new technologies in the fashion industry, our results suggest that users have become familiar with them and do not perceive them as difficult to use. Such positive attitudes could be an indicator of service popularity. As many scholars have pointed out [2, 23], our findings imply that AI technologies are becoming a part of our lives.

Meanwhile, the results of our CONCOR analysis suggest that perceptions of AI fashion curation services fall into three categories: shopping, platform, and business profit. In our analysis, the first group contained keywords such as "search," "product," "brand," and "style," which represent shopping activity. This implies that social media users perceive AI fashion curation services as places to search for information regarding products, brands, and styles while shopping. The second category, platform, consisted of keywords such as "fashion platform," "service," "application,” and "startup." Our findings thus suggest that social media users perceive AI fashion curation services as fashion platforms or applications. In addition, the fact that we extracted keywords such as "big data," "customizing," "analysis," and "individual" in the second group indicates that social media users may perceive AI fashion curation services as personalization services. The last category, business profit, included keywords such as "company," "investment," “development," and “stock," potentially implying that social media users perceive AI fashion curation services as related to the business field.

Along with the users' perceptions of AI fashion curation services, our analysis identified the important factors that lead to continuous use intentions. These include usability, usefulness, reliability, enjoyment, and personalization. This finding confirms the results of previous studies of AI technology adoption [32, 34], which identified usability, reliability, and usefulness as the key factors that influence AI adoption.

The findings of our study also support the results of a previous study [32] showing that hedonic motivation is the main factor influencing consumers' intentions to use AI systems in retail stores. In sum, these findings indicate that if people find AI fashion curation services fun and enjoyable, these feelings will positively influence their AI fashion curation service use intentions.

Meanwhile, in relation to AI fashion curation services, our findings indicated that personalization may be an important factor. This is because AI technology is used to maximize individuals' shopping experiences by providing personalized products, personalized recommendations, and personalized prices in the fashion market [36, 51], meaning satisfaction with personalization can play an important role in facilitating increased use of AI fashion curation services.

Our study identifies the uses and effects of AI fashion curation services by applying text mining method to reveal how consumers perceive them and how they intend to use them in the future. It offers several contributions to both theory and practice. Theoretically, it contributes new insights that broaden common perspectives of existing fashion curation research by including AI services.

In Korea, there have been some prior research conducted on user's motivations of AI service using big data [13]. However, there is a lack of research that examines AI based fashion curation service through text mining method using online postings from the social media. Even though some researchers have examined the perception of AI-based curation shopping services 
among users, they utilized survey method [35, 36]. Therefore, it makes our study more distinguished from the previous research. Social big data analysis allows researchers to examine the opinions expressed on social media and the features and aspects of today's society. Accordingly, we consider our study an initial step toward more advanced research examining the use of AI in the fashion industry.

In practice, by identifying key factors related to AI fashion curation service adoption from the customer perspective, our findings provide guidance for fashion organizations about which factors need to be implemented to increase the adoption of AI in the fashion industry. Additionally, our findings could also be used by decision makers seeking to implement measures that can support and increase AI adoption levels.

The limitations of this study include the fact that the online posts used for the analysis were only in Korean. Moreover, we extracted data using keywords related to AI fashion curation services, but the results concerned general opinions or perceptions of AI fashion curation services. We did not consider the specific platforms applying the AI fashion curation services. Future studies could extract data more effectively by using keywords specific to companies or famous brands associated with AI technologies. In addition, from the big data perspective, future research is needed to examine different countries such as the U.S., so that other results based on different measures can be generated.

\section{Acknowledgement}

This work was supported by Academic Support Project through National Research Foundation of Korea (NRF) funded by the Ministry of Humanities and Social sciences (2020S1A5B5A17088951).

\section{References}

[1] K. Schwab, The fourth industrial revolution, New York, NY, USA: Currency, 2017. Article (CrossRef Link)

[2] M. H. Huang and R. T. Rust, “Artificial intelligence in service,” Journal of Service Research, vol. 21, no. 2, pp.155-172, 2018. Article (CrossRef Link)

[3] M. T. Kotouza, S. F. Tsarouchis, A. C. Kyprianidis, A. C. Chrysopoulos, and P. A. Mitkas, “Towards fashion recommendation: An AI system for clothing data retrieval and analysis," in Proc. of International Conference on Artificial Intelligence Applications and Innovations (IFIP), pp. 433-444, 2020. Article (CrossRef Link)

[4] J. Lee, “Analysis on Trends of ICT-Based Fashion Tech Business Models," Journal of Theoretical and Applied Information Technology, vol. 97, no. 17, pp. 4659-4671, 2019. Article (CrossRef Link)

[5] M. Moosaei, Y. Lin, and H. Yang, "Fashion Recommendation and Compatibility Prediction Using Relational Network,” arXiv., May. 2020. Article (CrossRef Link)

[6] M. Bhaskar, Curation: The power of selection in a world of excess, London, UK: Piatkus, 2016. Article (CrossRef Link)

[7] J. W. Morris, "Curation by code: Infomediaries and the data mining of taste," European journal of cultural studies, vol. 18, no. 4-5, pp. 446-463, 2015. Article (CrossRef Link)

[8] L. Zhao and C. Min, "The rise of fashion informatics: A case of data-mining-based social network analysis in fashion,” Clothing and Textiles Research Journal, vol. 37, no. 2, pp. 87-102, 2019. Article (CrossRef Link)

[9] S. S. Sundar, "Rise of machine agency: A framework for studying the psychology of human-AI interaction (HAII),” Journal of Computer-Mediated Communication, vol. 25, no. 1, pp. 74-88, 2020. Article (CrossRef Link) 
[10] M. K. Lee, "Understanding perception of algorithmic decisions: Fairness, trust, and emotion in response to algorithmic management,” Big Data \& Society, vol. 5, no. 1, pp. 1-16, 2018. Article (CrossRef Link)

[11] N. Hu, T. Zhang, B. Gao, and I. Bose, "What do hotel customers complain about? Text analysis using structural topic model,” Tourism Management, vol. 72, pp. 417-426, 2019. Article (CrossRef Link)

[12] H. J. Ban \& H. Choi, E. K. Choi, S. Lee, and H. S. Kim, "Investigating Key Attributes in Experience and Satisfaction of Hotel Customer Using Online Review Data," Sustainability, vol. 11, no. 23, pp. 1-13, 2019. Article (CrossRef Link)

[13] D. Shin, "User perceptions of algorithmic decisions in the personalized AI system: perceptual evaluation of fairness, accountability, transparency, and explainability,” Journal of Broadcasting \& Electronic Media, vol. 64, no. 4, pp. 541-565, 2020. Article (CrossRef Link)

[14] S. Alsheibani, Y. Cheung, and C. Messom, “Artificial Intelligence Adoption: AI-readiness at FirmLevel,” in Proc. of Pacific Asia Conference on Information Systems (PACIS), pp. 37, 2018. Article (CrossRef Link)

[15] J. McCarthy, “Artificial intelligence, logic and formalizing common sense,” Philosophical Logic and Artificial Intelligence, pp. 161-190, 1989. Article (CrossRef Link)

[16] V. Shankar, "How artificial intelligence (AI) is reshaping retailing," Journal of Retailing, vol. 94, no. 4, pp. vi-xi, 2018. Article (CrossRef Link)

[17] T. H. Davenport and R. Ronanki, “Artificial intelligence for the real world,” Harvard Business Review, vol. 96, no. 1, pp. 108-116, 2018.Article (CrossRef Link)

[18] W. Andrews, “Applying Artificial Intelligence to Drive Business Transformation: A Gartner Trend Insight Report,” Gartner, Stamford, CT, USA, AUG. 29, 2017. [Online]. Available: https://www.gartner.com/en/documents/3792874/applying-artificial-intelligence-to-drivebusiness-trans

[19] P. Yunhe, “Heading toward Artificial Intelligence 2.0,” Engineering Journal, vol. 2, pp. 409-413. Article (CrossRef Link)

[20] M. Purdy and P. Daugherty, "Why artificial intelligence is the future of growth,” Accenture, 2016. [Online]. Available: https://dl.icdst.org/pdfs/files2/2aea5d87070f0116f8aaa9f545530e47.pdf

[21] R. Curran and B. Purcell, “TechRadarTM: Artificial Intelligence Technologies,” Forrester Research, Inc., Jan. $18, \quad 2017 . \quad$ [Online]. Available: https://businessdocbox.com/Business_Software/71658181-Techradar-artificial-intelligencetechnologies-q1-2017.html

[22] C. Hackl and S. G. Wolfe, Marketing New Realities: An Introduction to Virtual Reality \& Augmented Reality Marketing, Branding \& Communications, Toronto, Canada: Meraki Press 2017. Article (CrossRef Link)

[23] D. Bollier, "Artificial Intelligence Comes of Age: The Promise and Challenge of Integrating AI into Cars, Healthcare and Journalism,” Aspen Inst., Washington, DC, USA, Feb. 01, 2017. [Online]. Available: https://mediaimpact.issuelab.org/resources/26446/26446.pdf

[24] R. Tavakoli and P. Mura, "Netnography in tourism-Beyond web 2.0," Annals of Tourism Research, vol. 73, pp. 190-192, 2018. Article (CrossRef Link)

[25] D. Faggella, “Exploring the risks of artificial intelligence,” Crunch Network, 2016. Article (CrossRef Link)

[26] ReportLinker, “AI in Fashion Market Research Report by Product Type, by Component, by Deployment, by Application, by End User - Global Forecast to 2025 - Cumulative Impact of COVID-19,” ReportLinker, Mar. 01, 2021. [Online]. Available: https://www.globenewswire.com/news-release/2021/03/01/2184419/0/en/AI-in-Fashion-MarketResearch-Report-by-Product-Type-by-Component-by-Deployment-by-Application-by-End-UserGlobal-Forecast-to-2025-Cumulative-Impact-of-COVID-19.html

[27] A. L. Montgomery and M. D. Smith, "Prospects for Personalization on the Internet," Journal of Interactive Marketing, vol. 23, no. 2, pp. 130-137, 2009. Article (CrossRef Link)

[28] A. Newcomb, "New virtual store remodeling solution enables customer-driven store design and testing in a virtual reality environment,” Symphony RetailAI, Apr. 24, 2018. [Online]. Available: 
https://www.symphonyretailai.com/new-virtual-store-remodeling-enables-customer-driven-storedesign-testing/

[29] I. Tussyadiah and G. Miller, "Perceived impacts of artificial intelligence and responses to positive behaviour change intervention," in Proc. of Information and Communication Technologies in Tourism 2019, pp. 359-370, 2019. Article (CrossRef Link)

[30] K. Chopra, “Indian shopper motivation to use artificial intelligence: Generating Vroom's expectancy theory of motivation using grounded theory approach,” International Journal of Retail \& Distribution Management, Vol. 47, No. 3, pp. 331-347, 2019. Article (CrossRef Link)

[31] M. Saponaro, D. Le Gal, M. Gao, M. Guisiano, and I. C. Maniere, "Challenges and opportunities of artificial intelligence in the fashion world," in Proc. of 2018 International Conference on Intelligent and Innovative Computing Applications, pp. 1-5, 2018. Article (CrossRef Link)

[32] M. Niemelä, A. Arvola, and I. Aaltonen, "Monitoring the acceptance of a social service robot in a shopping mall: first results," in Proc. of The Companion of the 2017 ACM/IEEE International Conference on Human-robot Interaction, pp. 225-226, 2017. Article (CrossRef Link)

[33] S. Y. Song, “Modeling the consumer acceptance of retail service robots,” Ph.D. dissertation, Dept., Philosophy, Tennessee Univ., Knoxville, TN, USA, 2017. [Online]. Available: https://trace.tennessee.edu/cgi/viewcontent.cgi?article=5717\&context=utk_graddiss

[34] R. M. Stock and M. Merkle, "A service Robot Acceptance Model: User acceptance of humanoid robots during service encounters," in Proc. of 2017 IEEE International Conference on Pervasive Computing and Communications Workshops (PerCom Workshops), pp. 339-344, 2017. Article (CrossRef Link)

[35] H. An, S. Kwon, and M. Park, "A case study on the recommendation services for customized fashion styles based on artificial intelligence," Journal of the Korean Society of Clothing and Textiles, vol. 43, no. 3, pp. 349-360, 2019. Article (CrossRef Link)

[36] W. Choi, S. Cha, and S. M. Choi, "The Effects of Perceived Personalization and Need for Cognitive Closure on Consumers Curation Shopping Service Use Intention,” Advertising Research, vol. 119, pp. 89-122, 2018. Article (CrossRef Link)

[37] S. Wasserman and K. Faust, Social network analysis: Methods and applications, New York, NY, USA: Cambridge University Press, 1994.

[38] S. V. Gaikwad, A. Chaugule, and P. Patil, “Text mining methods and techniques,” International Journal of Computer Applications, vol. 85, no. 17, 2014. Article (CrossRef Link)

[39] S. Jusoh and H. M. Alfawareh, "Techniques, applications and challenging issue in text mining,” International Journal of Computer Science Issues (IJCSI), vol. 9, no. 6, pp. 431-436, 2012. Article (CrossRef Link)

[40] C. N. Jun and I. W. Seo, "Analyzing the Bigdata for Practical Using into Technology Marketing: Focusing on the Potential Buyer Extraction,” Journal of Marketing Studies, vol. 21, no. 2, pp. 181203, 2013. Article (CrossRef Link)

[41] C. Youn and H. J. Jung, "Semantic Network Analysis to Explore the Concept of Sustainability in the Apparel and Textile Industry,” Sustainability, vol. 13, no. 7, pp. 3813, 2021. Article (CrossRef Link)

[42] S. Beheshti-Kashi and K. D. Thoben, "The usage of social media text data for the demand forecasting in the fashion industry,” in Proc. of Dynamics in Logistics, pp. 723-727, 2016. Article (CrossRef Link)

[43] N. Rizun and W. Kucharska, “Text Mining Algorithms for Extracting Brand Knowledge. The fashion industry case,” The Fashion Industry Case, 2018. Article (CrossRef Link)

[44] H. An and M. Park, "A study on the evaluation of fashion design based on big data text analysisFocus on semantic network analysis of design elements and emotional terms," Journal of the Korean Society of Clothing and Textiles, vol. 42, no. 3, pp. 428-437, 2018. Article (CrossRef Link)

[45] M. Allahyari, S. Pouriyeh, M. Assefi, S. Safaei, E. D. Trippe, J. B. Gutierrez, and K. Kochut, "A brief survey of text mining: Classification, clustering and extraction techniques," in Proc. of KDD Bigdas, Halifax, Canada, 2017. Article (CrossRef Link)

[46] S. P. Borgatti, M. G. Everett, and L. C. Freeman, UCINET for Windows: Software for social network analysis, Needham, MA, USA: Analytic Technologies, 2002. Article (CrossRef Link) 
[47] S. Qaiser and R. Ali, "Text Mining: Use of TF-IDF to examine the relevance of words to document," International Journal of Computer Applications, vol. 181, no. 1, pp. 25-29, 2018. Article (CrossRef Link)

[48] M. Allahyari, S. Pouriyeh, M. Assefi, S. Safaei, E. D. Trippe, J. B. Gutierrez, and K. Kochut, "Text Summarization Techniques: A Brief Survey,” ArXiv, 2017. Article (CrossRef Link)

[49] C. E. Kim and J. H. Lee, "Trends of Big Data and Artificial Intelligence in the Fashion Industry," Journal of the Korean Society of Clothing and Textiles, vol. 42, no. 1, pp. 148-158, 2018. Article (CrossRef Link)

[50] F. D. Davis, R. P. Bagozzi, and P. R. Warshaw, "User acceptance of computer technology: A comparison of two theoretical models,” Management Science, vol. 35, no. 8, pp. 982-1028, 1989. Article (CrossRef Link)

[51] A. L. Montgomery and M. D. Smith, "Prospects for Personalization on the Internet," Journal of Interactive Marketing, vol. 23, no. 2, pp. 130-137, 2009. Article (CrossRef Link)

Eunjung Shin is a lecturer at Yonsei University in Seoul, South Korea. She received B.S. degree in Computer Engineering from EWHA Womans University, and M.S degree and Ph.D. degree in Clothing \& Textiles from Yonsei University. Her research interests involve Big Data Analysis, Artificial Intelligence and Consumer Behavior.

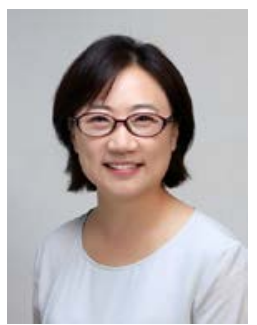

Ha Sung Hwang is a professor at Department of Media \& Communication at Dongguk University in Seoul, South Korea. She received her Ph.D. degree in Mass Media \& Communication at Temple University. Her research interests include social and psychological effects of communication technologies such as SNSs and Human-Computer Interaction. 